\title{
Early hemodynamic performance of the third generation St Jude Trifecta aortic prosthesis: A systematic review and meta-analysis
}

\author{
Kevin Phan, BS,,${ }^{a, b, c}$ Hakeem Ha, BMed, ${ }^{c}$ Steven Phan, BS, ${ }^{a}$ Martin Misfeld, MD, PhD, \\ Marco Di Eusanio, MD, PhD, ${ }^{\mathrm{a}, \mathrm{e}}$ and Tristan D. Yan, MBBS, $\mathrm{PhD}^{\mathrm{a}, \mathrm{f}}$
}

\section{ABSTRACT}

Objective: The Trifecta aortic prosthesis is a latest-generation trileaflet stented pericardial valve designed for supra-annular placement in the aortic position. Robust clinical evidence and long-term follow-up data for this new prosthesis are lacking; a systematic review was conducted to assess current evidence.

Methods: A comprehensive search from 6 electronic databases was performed, with time period parameters dating from database inception to January 2014. Results utilizing Trifecta prosthesis for aortic valve replacement (AVR) were identified.

Results: A total of 13 studies with 2549 patients undergoing AVR with this prosthesis were included in this review. The mean proportion of patients with aortic stenosis was $82.4 \%$, with a mean gradient of $47.4 \mathrm{~mm} \mathrm{Hg}$, and a pooled effective orifice area (EOA) of $0.74 \mathrm{~cm}^{2}$. Valve sizes of $21 \mathrm{~mm}$ and $23 \mathrm{~mm}$ were implanted in $71.3 \%$ of patients. The pooled rates of 30-day mortality, cerebrovascular accidents, and acute kidney injuries were $2.7 \%, 1.9 \%$, and $2.6 \%$, respectively. After implantation, the pooled mean gradient decreased to $9.2 \mathrm{~mm} \mathrm{Hg}$, whereas discharge EOA increased to $1.8 \mathrm{~cm}^{2}$, compared with preoperative parameters. Among included studies with significant heterogeneity detected, most patients had satisfactory patient-prosthesis mismatch, with $2.7 \%$ having severe mismatch.

Conclusions: The present systematic review demonstrated that short-term AVR with this prosthesis provided excellent early safety and hemodynamic outcomes with acceptable mean gradients and EOA. Long-term follow-up and randomized controlled trials are warranted to confirm the early results. (J Thorac Cardiovasc Surg 2015;149:1567-75)

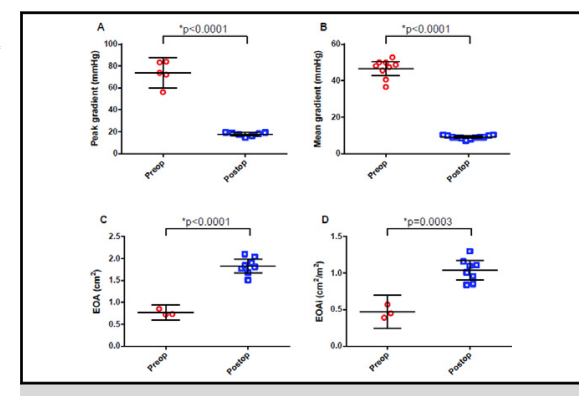

Significant improvement in all echocardiographic outcomes postoperatively.

\section{Central Message}

The present systematic review demonstrated that short-term Trifecta aortic valve replacement provided excellent results of early safety and haemodynamic outcomes with acceptable mean gradients and effective orifice area. Future long-term follow-up and randomized controlled trials are warranted to conform the early promising results of the Trifecta prosthesis.

\section{Perspective}

The Trifecta aortic prosthesis is a latest-generation trileaflet stented pericardial valve designed for supraannular placement in the aortic position. There is still a lack of robust clinical evidence and long-term follow-up data for this new prosthesis, thus a systematic review was conducted to assess the current evidence available. Pooled results from 13 studies and 2549 Trifecta prosthesis patients demonstrated excellent safety and haemodynamic outcomes in the shortterm, with acceptable mean gradients and effective orifice area. Future long-term follow-up and randomized control trials are warranted to conform the early promising results.

See Editorial Commentary page 1576.

See Editorial page 1483.

\footnotetext{
From The Collaborative Research (CORE) Group, ${ }^{\text {a }}$ Macquarie University, Sydney; Westmead Clinical School, ${ }^{\mathrm{b}}$ Sydney Medical School, The University of Sydney, Sydney; St Vincent's Clinical School, ${ }^{\mathrm{c}}$ The University of New South Wales, Syd-

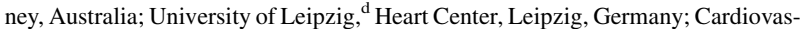
cular Surgery Department, ${ }^{\text {e }}$ Sant'Orsola-Malpighi Hospital, Bologna University, Bologna, Italy; and Department of Cardiothoracic Surgery, ${ }^{\mathrm{f}}$ Royal Prince Alfred Hospital, University of Sydney, Sydney, Australia.

K.P. is supported by an Australian Postgraduate Award (APA) at Macquarie University, Sydney, Australia.
}

Received for publication Sept 24, 2014; revisions received Jan 5, 2015; accepted for publication Jan 29, 2015; available ahead of print March 20, 2015.

Address for reprints: Tristan D. Yan, MBBS, PhD, The Collaborative Research (CORE) Group, Macquarie University Hospital; Macquarie University, 2 Technology Pl, Sydney, NSW, 2109 Australia (E-mail: tristanyan@annalscts.com). $0022-5223 / \$ 36.00$

Copyright (C) 2015 by The American Association for Thoracic Surgery http://dx.doi.org/10.1016/j.jtcvs.2015.01.043 


\section{Abbreviations and Acronyms \\ AVR = aortic valve replacement \\ CI $=$ confidence interval \\ EOA $=$ effective orifice area \\ EOAi $=$ effective orifice area index \\ EuroSCORE $=$ European System for Cardiac \\ Operative Risk Evaluation \\ PPM = patient-prosthesis mismatch}

Supplemental material is available online.

Although surgical aortic valve replacement (AVR) remains the gold standard as a treatment approach for patients with severe aortic stenosis, the design and efficacy of aortic valves have progressed and evolved with time. The latest generation of aortic valves has been manufactured with the aim of improving hemodynamic parameters and minimizing leaflet stress, while maintaining or improving the durability of previous valves.

The Trifecta (St Jude Medical Inc, St Paul, Minn) prosthesis is a third-generation, trileaflet, stented, pericardial valve designed for supra-annular placement in the aortic position. ${ }^{1,2}$ This prosthesis consists of bovine pericardial tissue mounted on a titanium stent, the purpose of which is to optimize direct tissue-to-tissue contact and reduce mechanical wear. The valve was approved by the US Food and Drug Administration in 2010, and some studies since have advocated its potential benefits, including claims of increased effective orifice area (EOA), reduced risk of abrasion and structural valve deterioration, as well as improved resistance to cardiac stress on leaflets. ${ }^{1,3-5}$ However, these potential benefits have yet to be verified by robust clinical evidence; randomized controlled studies and long-term follow-up data for this new prosthesis are still lacking.

Few single-center and multi-institutional studies have been conducted to investigate the efficacy and hemodynamic profile of this valve. To evaluate the current evidence

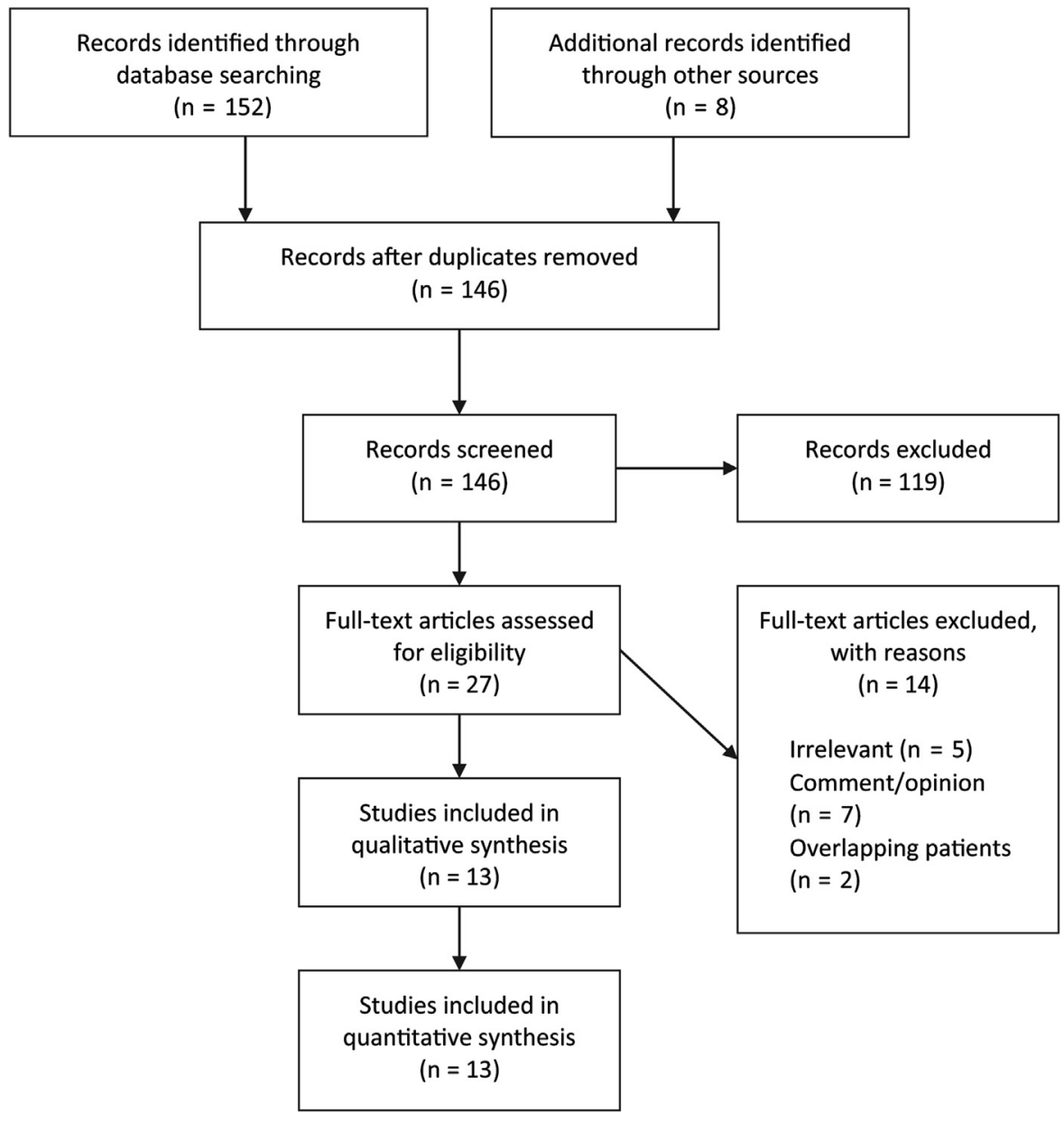

FIGURE 1. PRISMA flowchart of search strategy for studies investigating the aortic valve prosthesis. 
TABLE 1. Study characteristics

\begin{tabular}{|c|c|c|c|c|c|c|c|}
\hline First author & Year & Institution & Country & Study period & $\begin{array}{c}\text { Study } \\
\text { type }\end{array}$ & $\begin{array}{l}\text { Sample } \\
\text { size }(n)\end{array}$ & $\begin{array}{l}\text { Follow-up } \\
\text { (months) }\end{array}$ \\
\hline Yadlapati $^{8}$ & 2014 & $\begin{array}{l}\text { David Geffen School of Medicine, } \\
\text { University of California Los Angeles }\end{array}$ & United States & 2010-2012 & OS, $\mathrm{P}$ & 75 & $21.2 \pm 7.9$ \\
\hline Wendt $^{2}$ & 2014 & $\begin{array}{l}\text { West German Heart Centre Essen, } \\
\text { University Hospital Essen }\end{array}$ & Germany & 2003-2011 & OS, R & 121 & 6 \\
\hline Ugur $^{9}$ & 2014 & Mayo Clinic & United States & 2007-2009 & OS, $\mathrm{P}$ & 346 & 12 \\
\hline $\mathrm{Seo}^{10}$ & 2014 & Fukui Cardiovascular Centre & Japan & 2012 & OS, $\mathrm{P}$ & 23 & None \\
\hline Remadi $^{11}$ & 2014 & Amiens Hospital & France & 2011-2012 & OS, $\mathrm{P}$ & 100 & 12 \\
\hline Modi $^{12}$ & 2014 & Wessex Cardiothoracic Centre, Southampton & United Kingdom & 2011-2013 & OS, $\mathrm{P}$ & 400 & $12 \pm 7.44$ \\
\hline Maruyama $^{14}$ & 2014 & Juntedo University School of Medicine & Japan & 2012-2013 & OS, $\mathrm{R}$ & 33 & NR \\
\hline Levy $^{13}$ & 2014 & Amiens Hospital, Rennes Hospital, Angers Hospital & France & 2011-2012 & OS, $\mathrm{P}$ & 85 & 6 \\
\hline Bavaria $^{1}$ & 2014 & $\begin{array}{l}\text { Hospital for the University of Pennsylvania, } \\
\text { St Paul's Hospital, Vanderbilt Medical Centre, } \\
\text { Mission Health and Hospital, Herzzentrum Leipzig } \\
\text { GmbH, Mayo Clinic }\end{array}$ & $\begin{array}{l}\text { United States, } \\
\text { Canada, Germany }\end{array}$ & 2007-2009 & OS, $\mathrm{P}$ & 1014 & $10.8 \pm 5.4$ \\
\hline Permanyer $^{4}$ & 2013 & Hospiten Rambla & Spain & 2010-2012 & OS, $\mathrm{P}$ & 200 & None \\
\hline Minardi ${ }^{15}$ & 2013 & S. Camillo-Forlanini & Italy & 2011-2012 & OS, R & 50 & 6 \\
\hline Hanke $^{16}$ & 2013 & University Clinic of Schleswig-Holstein & Germany & 2010-2012 & OS, R & 32 & $5 \pm 2$ \\
\hline Dell'Aquila $^{5}$ & 2013 & Universitatsklinikum Munster & Germany & 2010-2011 & OS, R & 70 & None \\
\hline
\end{tabular}

$O S$, Observational study; $P$, prospective; $R$, retrospective; $N R$, not reported. *Follow-up expressed as mean \pm standard deviation.

for early outcomes and hemodynamic profile with this prosthesis, the present systematic review was performed.

\section{METHODS}

\section{Literature Search Strategy}

Electronic searches were performed using Ovid MEDLINE, PubMed, Cochrane Central Register of Controlled Trials, Cochrane Database of Systematic Reviews, ACP (American College of Physicians) Journal Club, and the Database of Abstracts of Review of Effectiveness (DARE), encompassing the time period from the dates of inception to January 2014. To achieve maximum sensitivity with the search strategy, we combined the following terms, as either key words or MeSH (medical subject headings) terms: "Trifecta" AND "aortic valve" OR "surgery OR operation OR replacement." An example of the precise search strategy is provided in Appendix E1.

The reference lists of all retrieved articles were reviewed for further identification of potentially relevant studies, assessed using the inclusion and exclusion criteria. Additionally, we considered whether we knew of any unpublished data. The study selection process and reporting process was performed according to the PRISMA (Preferred Reporting Items for Systematic Reviews and Meta-Analyses) statement. ${ }^{6}$

\section{Selection Criteria}

Eligible studies for the present systematic review and metaanalysis included those in which patient cohorts underwent AVR with a

TABLE 2. Operative characteristics

\begin{tabular}{|c|c|c|c|c|c|c|c|c|c|c|c|c|c|c|c|}
\hline \multirow[b]{2}{*}{ First author } & \multicolumn{2}{|c|}{$\begin{array}{l}\text { Aortic crossclamp } \\
\text { time (min) }\end{array}$} & \multicolumn{2}{|c|}{$\begin{array}{l}\text { Cardiopulmonary } \\
\text { bypass time (min) }\end{array}$} & \multirow{2}{*}{$\begin{array}{c}\text { Isolated } \\
\text { AVR } \\
(\%)\end{array}$} & \multicolumn{2}{|c|}{$\begin{array}{c}\text { Concomitant } \\
(\%) \\
\end{array}$} & \multirow{2}{*}{$\begin{array}{c}\text { Aortic root } \\
\text { enlargement } \\
(\%)\end{array}$} & \multirow{2}{*}{$\begin{array}{c}\text { Septal myo- } \\
\text { mectomy } \\
(\%)\end{array}$} & \multicolumn{6}{|c|}{ Valve size in $\mathrm{mm}(\%)$} \\
\hline & All & AVR only & All & AVR only & & Valve & CABG & & & 19 & 21 & 23 & 25 & 27 & 29 \\
\hline Yadlapati $^{8}$ & NR & NR & NR & NR & NR & 10 & 17.1 & 0 & NR & NR & NR & NR & NR & NR & NR \\
\hline Wendt $^{2}$ & $85 \pm 30$ & NR & $127 \pm 52$ & NR & NR & 32.2 & 53.7 & 9.1 & 19.8 & 4.9 & 21.5 & 33.9 & 28.1 & 8.3 & 3.3 \\
\hline Ugur $^{9}$ & $81.4 \pm 36.5$ & $64.0 \pm 25.0$ & $106.9 \pm 47.8$ & $84.7 \pm 34.8$ & 45.4 & NR & 35.5 & NR & NR & 28 & 72 & 0 & 0 & 0 & 0 \\
\hline $\mathrm{Seo}^{10}$ & $97 \pm 19$ & NR & $148 \pm 36$ & NR & 26 & 17.4 & 39.1 & 13.1 & NR & 17.4 & 52.2 & 30.4 & 0 & 0 & 0 \\
\hline Remadi $^{11}$ & $42.9 \pm 18.1$ & $31 \pm 20.2$ & $63.72 \pm 29$ & $45.5 \pm 20.7$ & 59 & 3 & 36 & 2 & NR & 4 & 43 & 37 & 12 & 4 & 0 \\
\hline Modi $^{12}$ & $76 \pm 30.3$ & $62 \pm 18.9$ & $104.4 \pm 43.6$ & $83.7 \pm 25.8$ & 48 & 6 & 39 & 0.5 & 1 & 7 & 40 & 34 & 15 & 3.5 & 0.5 \\
\hline Maruyama $^{14}$ & $85(40)$ & NR & $95(46)$ & NR & NR & 27.3 & 18.2 & 24.2 & 18.2 & 27.3 & 45.5 & 21.2 & 6.1 & 0 & 0 \\
\hline Levy $^{13}$ & $40 \pm 12$ & NR & $61 \pm 22$ & NR & NR & NR & 29.4 & NR & NR & 5.9 & 42.4 & 36.5 & 12.9 & 2.4 & 0 \\
\hline Bavaria $^{1}$ & $83.2 \pm 37.3$ & $64.3 \pm 25.5$ & $111.5 \pm 51.0$ & $86.6 \pm 35.8$ & 42.2 & 6 & 36.7 & 1.7 & NR & NR & NR & NR & NR & NR & NR \\
\hline Permanyer $^{4}$ & NR & NR & NR & NR & 56.5 & 10.5 & 27.5 & 5.5 & 0 & 16.5 & 40.5 & 29.5 & 11.5 & 2 & 0 \\
\hline Minardi ${ }^{15}$ & $62 \pm 22$ & NR & $78 \pm 22$ & NR & 64 & 6 & 24 & 0 & 6 & 18 & 46 & 30 & 6 & 0 & 0 \\
\hline Hanke $^{16}$ & $150.22 \pm 54.77$ & NR & NR & NR & 28.1 & 21.9 & 46.9 & NR & NR & 9.4 & 25 & 46.9 & 18.8 & NR & NR \\
\hline Dell'Aquila $^{5}$ & $74.95 \pm 22.18$ & $65.42 \pm 13.93$ & $113.31 \pm 32.45$ & $102.04 \pm 23.30$ & 60 & 1.4 & 35.7 & 0 & 1.4 & 11.4 & 30 & 25.7 & 27.1 & 5.7 & 0 \\
\hline Minimum & 40 & 31 & 61 & 45.5 & 26 & 1.4 & 17.1 & 0 & 0 & 4 & 21.5 & 0 & 0 & 0 & 0 \\
\hline Maximum & 150 & 65.4 & 148 & 102 & 64 & 32.2 & 53.7 & 24.2 & 19.8 & 28 & 72 & 46.9 & 28.1 & 8.3 & 3.3 \\
\hline $\begin{array}{l}\text { Pooled } \\
\text { weighted } \\
\text { average }\end{array}$ & 78.7 & 62.1 & 105.8 & 84.1 & 46.4 & 8.5 & 35.8 & 2.6 & 4.3 & 14.1 & 46.2 & 25.1 & 11.6 & 2.7 & 0.4 \\
\hline
\end{tabular}

$A V R$, Aortic valve replacement; $C A B G$, coronary artery bypass graft surgery; $N R$, not reported. 


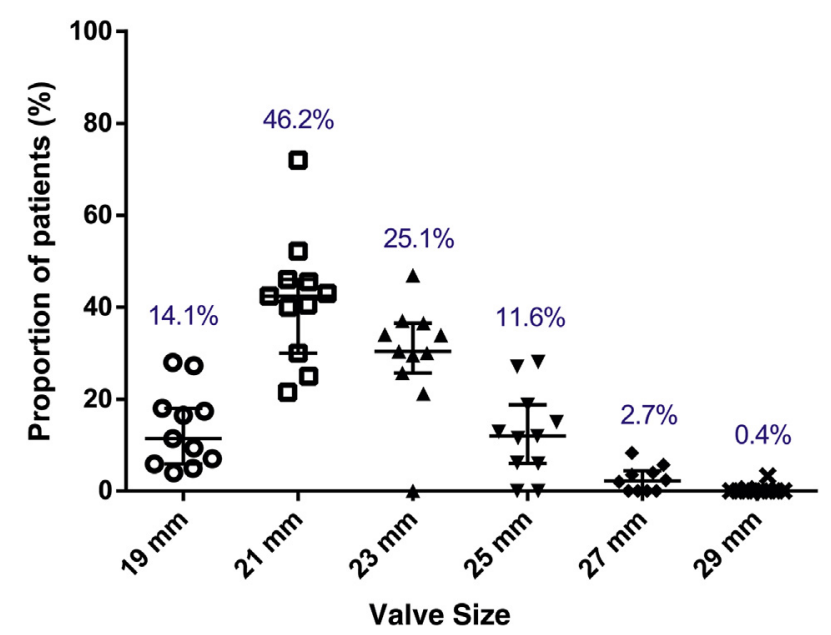

FIGURE 2. Pooled proportions of patients who received prostheses of the following sizes (mm): 19, 21, 23, 25, 27, and 29. Each individual point denotes the mean $\%$ reported by an included study. The 3 horizontal bars for each valve size represent median and interquartile range. The percentage above the bars is the overall proportion.

third-generation Trifecta prosthesis (St Jude Medical Inc, St Paul, Minn). Studies that did not include mortality or complications as endpoints were excluded. When institutions published duplicate studies with accumulating numbers of patients or longer follow-up periods, only the most complete reports were included for quantitative assessment at each time interval. In addition, reference lists were hand-searched for further relevant studies. All publications were limited to those that involve human subjects and are written in English. Abstracts, case reports, conference presentations, editorials, reviews, and expert opinions were excluded.

\section{Data Extraction and Critical Appraisal}

Data extraction was conducted with a standardized data collection form. All data were extracted from article texts, tables, and figures. Two investigators independently reviewed each retrieved article, and selection of relevant articles for the meta-analysis was done by discussion and consensus according to inclusion and exclusion criteria. Two investigators independently performed the extraction of data. Discrepancies were resolved by discussion and consensus.

Because quality scoring is controversial in the meta-analysis of observational studies, 2 investigators independently appraised each article included in the meta-analysis according to a critical review checklist from the Dutch Cochrane Center, as proposed by the Meta-analysis of Observational Studies in Epidemiology (MOOSE) group. ${ }^{7}$ The key points on this checklist include: (1) a clear definition of the study population; (2) a clear definition of outcomes and outcome assessment; (3) an independent assessment of outcome parameters; (4) a sufficient follow-up duration; (5) no selective loss during follow-up; and (6) identification of important confounders and prognostic factors. The final results were reviewed by the investigators.

\section{Statistical Analysis}

A meta-analysis of proportions was conducted for the available main perioperative and postoperative variables. First, to establish variance of raw proportions, a Freeman-Tukey transformation was applied. To incorporate heterogeneity (anticipated among the included studies), transformed proportions were combined using DerSimonian-Laird random effects models. Heterogeneity between trials was studied using $\chi^{2}$ analysis. The $\mathrm{I}^{2}$ statistic was used to estimate the percentage of total variation across studies that was due to heterogeneity rather than chance. This statistic
}

can be calculated as: $\mathrm{I}^{2}=100 \% \times(\mathrm{Q}-\mathrm{df}) / \mathrm{Q}$, with Q defined as Cochrane's heterogeneity statistic, and df defined as degrees of freedom. An $\mathrm{I}^{2}$ value of $>50 \%$ was considered to represent substantial heterogeneity. All these analyses were performed using Open Meta-Analyst and the metafor package for $\mathrm{R}$, version 3.01 .

\section{RESULTS}

From the systematic search of 6 databases and other sources, 146 studies were identified and screened. After exclusion of duplicates and irrelevant articles, 27 studies remained for detailed assessment. Finally, 13 studies were included for systematic review and meta-analysis of proportions, including 2549 patients who underwent AVR with this prosthesis, for assessment (Figure 1). Quality assessment using the MOOSE checklist criteria is summarized in Table E1.

All 13 included articles were observational studies, including 8 prospective $\mathrm{e}^{1,4,8-13}$ and 5 retrospective

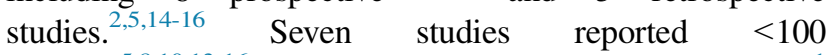
patients, $^{5,8,10,13-16}$ and 1 study reported $>1000$ patients. $^{1}$ Four included studies ${ }^{4,5,15,16}$ were published in 2013, and 9 studies $^{1,2,8-14}$ were published in 2014. The mean follow-up time was up to 6 months for 4 studies, $, 13,15,16$ up to 12 months for 4 studies, ${ }^{1,9,11,12}$ and $>20$ months for 1 study $^{8}$ (Table 1).

For procedural parameters, aortic crossclamp durations were reported in 11 studies; cardiopulmonary bypass duration was reported in 10 studies. Discharge peak gradient, mean gradient, EOA and EOA index (EOAi) were reported in $7,12,8$, and 8 studies, respectively. The 30-day mortality was reported in 9 studies.

\section{Baseline Patient Characteristics}

The 13 included studies had, overall, $54.7 \%$ male patients, with a mean age of 73.7 years (range: 71-76). The mean body surface area was $1.9 \mathrm{~m}^{2}$ (range: $1.49-1.95$ ). The mean proportion of patients with aortic stenosis was $82.4 \%$. The mean left ventricular ejection fraction of included patients was $57.7 \%$ (range: $50.5 \%-63.3 \%$ ). Most patients had coronary artery disease, hypertension, and hyperlipidemia (weighted mean: $53.1 \%, 77.1 \%$, and $61.5 \%$, respectively). Other comorbidities included diabetes $(24.8 \%)$, chronic lung disease $(13.6 \%)$, pulmonary hypertension $(16 \%)$, atrial fibrillation $(6.7 \%)$, chronic kidney disease $(8.0 \%)$ and peripheral vascular disease $(12.4 \%)$. Prior surgery was performed in $18.6 \%$ of included patients. Risk assessment using logistic versus additive EuroSCORE (European System for Cardiac Operative Risk Evaluation) was inconsistent among included studies, and thus a mean EuroSCORE could not be validly calculated (Table E2).

The weighted mean crossclamp duration was 78.7 minutes (range: 40-150) and 62.1 minutes (range: 31-65.4) for isolated AVR. For cardiopulmonary bypass, the weighted mean was 105.8 minutes (range: 61-148) for 


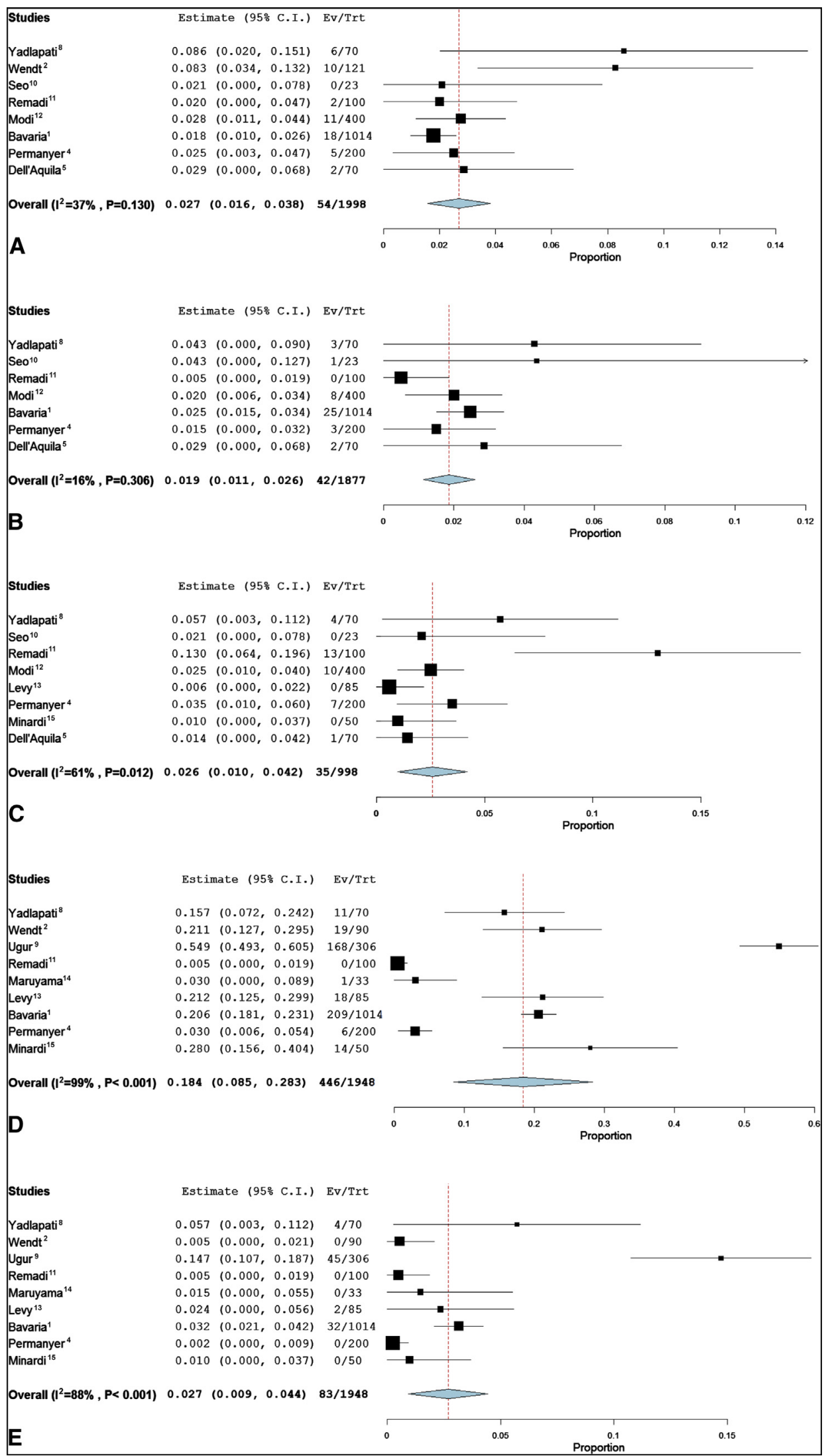

FIGURE 3. In patients undergoing aortic valve replacement using the prosthesis, the forest plot shows: (A) 30-day mortality; (B) cerebrovascular accidents; (C) acute kidney injury; (D) moderate patient-prosthesis mismatch; and (E) severe patient-prosthesis mismatch. C.I., Confidence interval; Ev, events number; $T r t$, treatment number. 


\begin{tabular}{|c|c|c|c|c|c|c|c|c|c|c|c|c|c|c|c|c|c|}
\hline & \multirow[b]{2}{*}{$\begin{array}{c}\text { 30-d } \\
\text { mortality }\end{array}$} & \multirow[b]{2}{*}{ CVA } & \multirow[b]{2}{*}{ MI } & \multirow[b]{2}{*}{ Infection } & \multirow[b]{2}{*}{ AKI } & \multirow[b]{2}{*}{$\begin{array}{c}\text { AV } \\
\text { block }\end{array}$} & \multirow[b]{2}{*}{ Bleeding } & \multirow[b]{2}{*}{$\begin{array}{c}\text { Blood } \\
\text { transfusion }\end{array}$} & \multirow[b]{2}{*}{ Re-op } & \multirow[b]{2}{*}{$\begin{array}{c}\text { New } \\
\text { AF }\end{array}$} & \multirow[b]{2}{*}{$\begin{array}{l}\text { Low } \\
\text { CO }\end{array}$} & \multirow[b]{2}{*}{ PVL } & \multirow[b]{2}{*}{$\begin{array}{c}\text { ICU } \\
\text { stay (days) }\end{array}$} & \multicolumn{3}{|c|}{ Rehosp } & \multirow[b]{2}{*}{$\begin{array}{r}\text { Severe } \\
\text { PPM }\end{array}$} \\
\hline & & & & & & & & & & & & & & $\begin{array}{c}\text { Hospital } \\
\text { stay } \\
\text { (days) }\end{array}$ & $\begin{array}{c}\text { for } \\
\text { valve } \\
\text { issues }\end{array}$ & $\begin{array}{c}\text { Moderate } \\
\text { PPM }\end{array}$ & \\
\hline Yadlapati $^{8}$ & 8.6 & 4.3 & 0 & NR & 5.7 & NR & 2.9 & NR & NR & NR & NR & NR & NR & NR & 1.43 & 15.7 & 5.7 \\
\hline Wendt $^{2}$ & 8.3 & NR & NR & NR & NR & NR & NR & NR & NR & NR & NR & NR & NR & NR & NR & 21 & 0 \\
\hline Ugur $^{9}$ & NR & NR & NR & NR & NR & NR & NR & NR & NR & NR & NR & NR & NR & NR & NR & 54.9 & 14.7 \\
\hline $\mathrm{Seo}^{10}$ & 0 & 4 & 0 & 0 & 0 & 0 & 0 & 0 & 0 & 0 & 0 & 0 & NR & NR & 0 & NR & NR \\
\hline $\operatorname{Remadi}^{11}$ & 2 & 0 & 0 & 0 & 13 & 8 & 0 & 0 & 1 & 42 & 0 & 3 & $3.38 \pm 2.44$ & $11 \pm 4.7$ & NR & 0 & 0 \\
\hline $\operatorname{Modi}^{12}$ & 2.8 & 2 & NR & NR & 2.5 & NR & NR & NR & NR & NR & NR & 0 & NR & $10(5-62)$ & NR & NR & NR \\
\hline Maruyama $^{14}$ & NR & NR & NR & NR & NR & NR & NR & NR & NR & NR & $\mathrm{NR}$ & 0 & NR & NR & NR & 3 & 0 \\
\hline Levy $^{13}$ & NR & 0 & 0 & 0 & 0 & 0 & 0 & 0 & 0 & NR & $\mathrm{NR}$ & 6 & NR & NR & NR & 21.2 & 2.3 \\
\hline Bavaria $^{1}$ & 1.8 & 2.5 & NR & NR & NR & NR & 8.1 & NR & 0.1 & NR & NR & 0.1 & NR & NR & NR & 22.8 & 5.5 \\
\hline Permanyer $^{4}$ & 2.5 & 1.5 & NR & 1 & 3.5 & 2 & NR & NR & 0.5 & 18 & NR & NR & 1.5 & 8.5 & NR & 3 & 0 \\
\hline Minardi $^{15}$ & NR & NR & 0 & NR & 0 & NR & NR & NR & 2 & 8 & NR & NR & NR & NR & NR & 28 & 0 \\
\hline Hanke $^{16}$ & NR & NR & NR & NR & NR & NR & NR & NR & NR & NR & NR & NR & NR & NR & NR & NR & NR \\
\hline Dell'Aquila $^{5}$ & 2.9 & 2.9 & 1.4 & 1.4 & 1.4 & 4.2 & 0 & 0 & 10 & NR & NR & 1.4 & NR & NR & NR & NR & NR \\
\hline Minimum & 0 & 0 & 0 & 0 & 0 & 0 & 0 & 0 & 0 & 0 & NA & 0 & NA & NA & NA & 0 & 0 \\
\hline Maximum & 8.6 & 4.3 & 1.4 & 1.4 & 13 & 8 & 8.1 & 0 & 10 & 42 & NA & 6 & NA & NA & NA & 54.9 & 14.7 \\
\hline Pooled weighted & 2.7 & 1.9 & 0.2 & 0.6 & 2.6 & 3.1 & 6.2 & 0 & 0.7 & 22.0 & NA & 0.6 & NA & NA & NA & 18.4 & 2.7 \\
\hline
\end{tabular}

Values are $\%$, unless otherwise indicated. Moderate PPM is defined as EOAi $<0.8$. Severe PPM is defined as EOAi $<0.65 . C V A$, Cerebrovascular accident; $M I$, myocardial infarc tion; $A K I$, acute kidney injury; $A V$, atrioventricular; Re-op, reoperation; $A F$, atrial fibrillation; $C O$, cardiac output; $P V L$, paravalvular leak; $I C U$, intensive care unit; Rehosp, rehospitalization; $P P M$, patient-prosthesis mismatch; $N R$, not reported; $N A$, not available.

all Trifecta cases, and 84.1 minutes (range: 45.5-102) for isolated procedures. Concomitant valve procedures were performed in $8.5 \%$ of patients; concomitant coronary artery bypass grafting was performed in $35.8 \%$ of patients. The proportions of patients with valve sizes of 19, 21, 23, 25, 27, and $29 \mathrm{~mm}$, respectively, are shown in Table 2 and Figure 2.

Before AVR, the mean baseline peak gradient was 73.9 $\mathrm{mm} \mathrm{Hg} \mathrm{(95 \%} \mathrm{confidence} \mathrm{interval} \mathrm{[CI],} \mathrm{68.3-79.6),} \mathrm{whereas}$ the mean gradient was $47.4 \mathrm{~mm} \mathrm{Hg}(95 \% \mathrm{CI}, 45.1-49.7)$. The pooled EOA was $0.74 \mathrm{~cm}^{2}(95 \% \mathrm{CI}, 68.8-79.8)$, and the pooled EOAi was $0.475 \mathrm{~cm}^{2} / \mathrm{m}^{2}(95 \% \mathrm{CI}, 0.30-0.65)$.

\section{Assessment of Safety}

The pooled weighted mean of the 30-day mortality rate was $2.7 \%(95 \% \mathrm{CI}, 1.6 \%-3.8 \%)$ (Figure 3, A). From 1877 patients, the pooled rate of cerebrovascular accidents was $1.9 \%(95 \%$ CI, $1.1 \%-2.6 \%)$ (Figure $3, B)$, whereas the pooled rate of acute kidney injuries was $2.6 \%(95 \% \mathrm{CI}$, $1.0 \%-4.2 \%$ ) (Figure 3, C). Other perioperative outcomes, including myocardial infarctions, bleeding rates, blood transfusion requirements, reoperations, new atrial fibrillation, paravalvular leakage, intensive care unit stay, hospital stay, and rehospitalizations are summarized in Table 3.

\section{Assessment of Hemodynamic Outcomes}

All included studies reported echocardiographic hemodynamic outcomes. The pooled peak gradient was 17.7 $\mathrm{mm} \mathrm{Hg}$ (95\% CI, 16.3-19.2); the pooled mean gradient was $9.2 \mathrm{~mm} \mathrm{Hg}(95 \% \mathrm{CI}, 8.7-9.6)$. The pooled discharge EOA was $1.8 \mathrm{~cm}^{2}(95 \% \mathrm{CI}, 1.6-2.0)$; the EOAi was 1.0 $\mathrm{cm}^{2} / \mathrm{m}^{2}$ (95\% CI, 0.9-1.1). Summary of peak gradient, mean gradient, EOA, and EOAi, stratified according to valve size, is provided in Figure 4 and Table 4.

Among the studies that defined moderate patientprosthesis mismatch (PPM), the cutoff of EOAi of $<0.8$ was uniformly reported. Nine studies defined severe PPM as an EOAi of $<0.65$; and 5 studies did not report definitions for severe PPM. Accordingly, there was moderate PPM in $18.4 \%$ (95\% CI, 8.5\%-28.3\%) (Figure 3, D); severe PPM was evident in 2.7\% (95\% CI, $0.9 \%-4.4 \%$ ) of included patients (Figure 3,E). Significant heterogeneity among included studies was detected for PPM outcomes.

\section{COMMENT}

The prosthesis was CE (Conformité Européenne) approved and introduced into clinical practice in 2011, with the aim of providing better hemodynamic profiles, while maintaining the durability and efficacy of previous bioprostheses. Given its recent introduction, few studies have reported on the valve's long-term durability, efficacy, and safety outcomes. The present systematic review assessed the early safety and hemodynamic outcomes of this aortic prosthesis from available evidence.

Although long-term durability and hemodynamic data for the prosthesis are currently unavailable, a few short-term studies demonstrate promising performance, but these require further validation. This valve consists of a sewing ring and supra-annular design, which has been previously suggested to reduce flow obstruction ${ }^{5}$ by better matching the internal diameter to the tissue annulus diameter. As with other third-generation aortic valves, this 

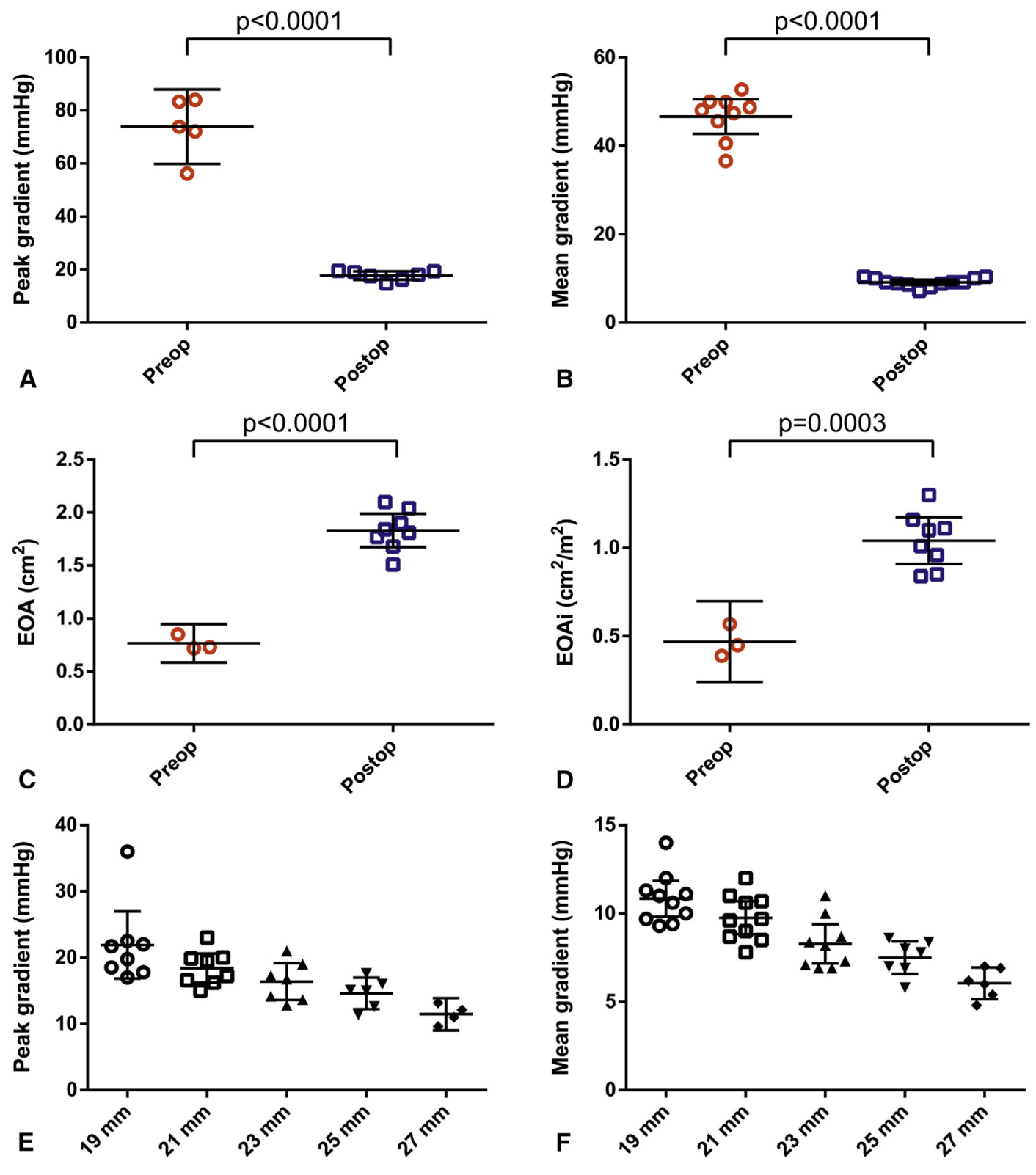

Valve Size
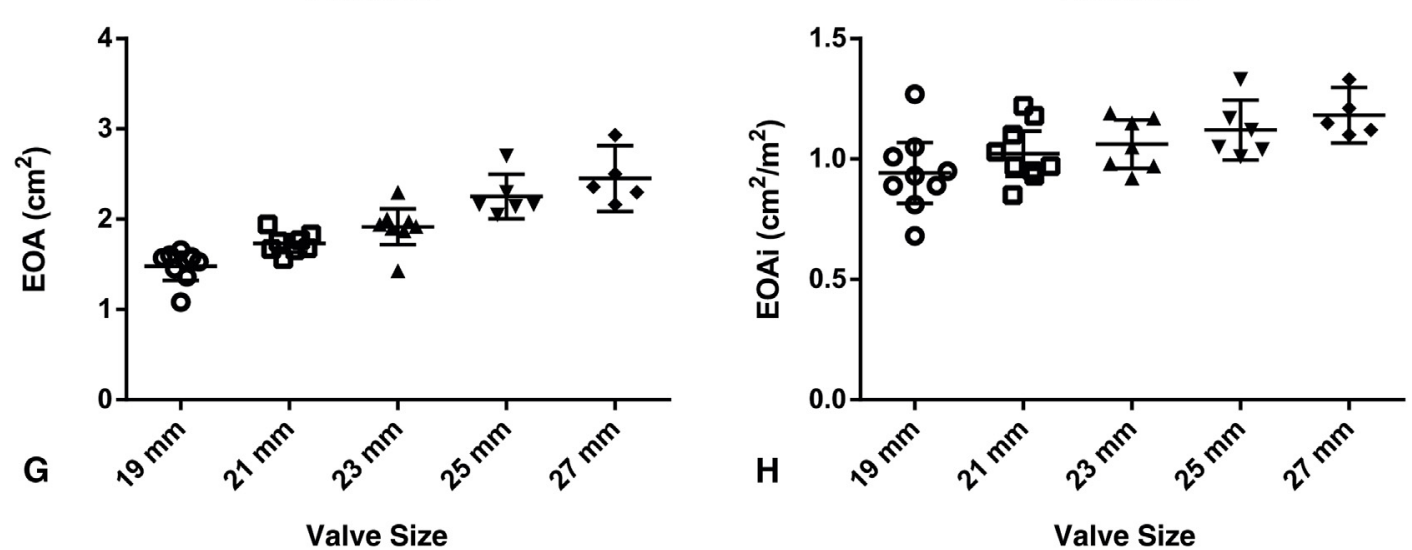

FIGURE 4. A-H, Summary of discharge echocardiographic findings of the present systematic review, stratified by valve size. Pooled weighted mean valves represented as mean (95\% confidence interval). Preop, Preoperative; Postop, postoperative; EOA, effective orifice area; EOA $i$, effective orifice area index. 
TABLE 4. Pooled weighted mean estimates of hemodynamic function

\begin{tabular}{|c|c|c|c|}
\hline Hemodynamic outcome by valve size & $\mathbf{n}$ & $\mathbf{N}$ & $\begin{array}{c}\text { Weighted } \\
\text { pooled proportion } \\
\text { or estimate }(95 \% \mathrm{CI} \\
\end{array}$ \\
\hline \multicolumn{4}{|l|}{$19 \mathrm{~mm}$} \\
\hline Peak gradient (mm Hg) & 182 & 7 & $22.0(18.7,25.4)$ \\
\hline Mean gradient $(\mathrm{mm} \mathrm{Hg})$ & 182 & 7 & $10.7(10.0,11.5)$ \\
\hline EOA & 154 & 7 & $1.44(1.3,1.56)$ \\
\hline EOAi & 154 & 7 & $0.89(0.78,1.01)$ \\
\hline \multicolumn{4}{|l|}{$21 \mathrm{~mm}$} \\
\hline Peak gradient $(\mathrm{mm} \mathrm{Hg})$ & 575 & 7 & $18.5(17.0,20.1)$ \\
\hline Mean gradient $(\mathrm{mm} \mathrm{Hg})$ & 575 & 7 & $10.0(9.1,10.9)$ \\
\hline EOA & 472 & 7 & $1.72(1.61,1.83)$ \\
\hline EOAi & 472 & 7 & $1.00(0.90,1.10)$ \\
\hline \multicolumn{4}{|l|}{$23 \mathrm{~mm}$} \\
\hline Peak gradient (mm Hg) & 253 & 7 & $16.7(14.0,19.4)$ \\
\hline Mean gradient $(\mathrm{mm} \mathrm{Hg})$ & 284 & 7 & $8.7(7.6,9.7)$ \\
\hline $\mathrm{EOA}$ & 168 & 6 & $2.00(1.85,2.15)$ \\
\hline EOAi & 168 & 6 & $1.07(0.97,1.16)$ \\
\hline \multicolumn{4}{|l|}{$25 \mathrm{~mm}$} \\
\hline Peak gradient $(\mathrm{mm} \mathrm{Hg})$ & 118 & 5 & $14.8(13.2,16.4)$ \\
\hline Mean gradient $(\mathrm{mm} \mathrm{Hg})$ & 118 & 5 & $7.6(7.1,8.1)$ \\
\hline EOA & 63 & 5 & $2.27(2.11,2.42)$ \\
\hline EOAi & 168 & 6 & $1.10(1.01,1.18)$ \\
\hline \multicolumn{4}{|l|}{$27 \mathrm{~mm}$} \\
\hline Peak gradient (mm Hg) & 28 & 4 & $11.3(8.9,13.8)$ \\
\hline Mean gradient $(\mathrm{mm} \mathrm{Hg})$ & 30 & 5 & $6.0(4.9,7.0)$ \\
\hline EOA & 16 & 4 & $2.50(2.40,2.59)$ \\
\hline EOAi & 16 & 4 & $1.15(1.12,1.18)$ \\
\hline
\end{tabular}

$n$, Number of patients analyzed; $N$, number of studies included in analysis; $C I$, confidence interval; $E O A$, effective orifice area; $E O A i$, effective orifice area index.

prosthesis includes an anticalcification agent, either glutaraldehyde or ethanol. ${ }^{1}$ The valve design, with the pericardial leaflets mounted externally to the stent frame, is meant to increase EOA and hemodynamic performance. In addition, the valve has been claimed to have inherent distensibility, ${ }^{8}$ to promote optimal function and durability in periods of duress and high load, such as during exercise.

From early postoperative outcomes, the prosthesis seems to be safe, with a low 30 -day mortality rate of $2.7 \%$. This rate occurred despite $8.5 \%$ of patients undergoing concomitant valve surgery, and $35.8 \%$ undergoing concomitant bypass grafting. Given that all included studies were published between 2013 and 2014, the low mortality rate supports improved and excellent outcomes after conventional AVR in the modern era. Other complications, including infection $(0.6 \%)$, reoperations $(0.7 \%)$, and paravalvular leaks $(0.6 \%)$, were also low, suggesting that early outcomes with the valve are safe. The multicenter study of 1014 patients who received the valve reported a single case of early explantation that was needed because of structural valve degeneration. ${ }^{1}$ In another recent case report by Saxena and colleagues, ${ }^{17}$ structural valve degeneration with prosthesis thickening and calcification was evident after 4-year follow-up of 1 patient.
The present systematic review demonstrates promising short-term valve hemodynamics, with a pooled mean gradient of $9.2 \mathrm{~mm} \mathrm{Hg}$, and a pooled discharge EOA of 1.8 $\mathrm{cm}^{2}$. Although these short-term results suggest that the valve has the potential to provide excellent hemodynamic outcomes, the available evidence is not propensity-matched or randomized, and long-term follow-up evidence is very limited. Furthermore, the direct comparative data between this and other prostheses, such as the Mitroflow (Sorin Group, Saluggio, Italy), the Mosaic (Medtronic, Inc, Minneapolis, Minn), and the Magna (Edwards LifeSciences, Irvine, Calif), are insufficient to yield valid statistical comparisons.

As shown in Figure 4, EOA and EOAi show an increasing trend as size of the prosthesis increases, which coincides with decreasing trends of peak and mean gradients. Additionally, $>60 \%$ of the Trifecta prostheses were sized at $19 \mathrm{~mm}$ or $21 \mathrm{~mm}$ and implanted in patients with a small annulus, in contrast with the valve-size distribution reported $^{18,19}$ with other valves, such as the Perimount Magna (Edwards LifeSciences, Irvine, Calif). Although no concrete comparative conclusions can be drawn, these trends do suggest that the valve may provide good hemodynamic performance. These early outcomes require further validation and confirmation in clinically robust, well-designed, and well-organized multicenter studies.

The influence of PPM on patient prognosis is controversial, with some studies showing increased all-cause and cardiac mortality in this setting. ${ }^{20,21}$ Given that finding, PPM prevention and minimization is becoming increasingly important when choosing which valve prosthesis to implant. Previously, low PPM could be achieved by using only stentless prostheses ${ }^{22}$; however, their implantation is technically difficult and is associated with a steep learning curve. Furthermore, stentless prostheses are associated with extended crossclamp and cardiopulmonary bypass durations, ${ }^{23}$ and they do not favor minimally invasive approaches. In addition, reoperations with stentless valves are more extensive and demanding, often requiring aortic root replacement. ${ }^{24}$

For these reasons, stented valves are still used by most surgeons, despite the less favorable hemodynamic properties and a revived interested in stentless valves in the early 1990s. Although data reported on PPM may vary, our review suggests that the prosthesis is associated with excellent early EOA and mean gradients, and a low incidence of severe PPM of $2.7 \%$, which is considerably lower than the $9.8 \%$ incidence in the general population underoing AVR. ${ }^{21}$

Another known limitation of the prosthesis is that structural deviations occur during implantation that may result in suboptimal hemodynamics. This prosthesis has a very high profile, with pericardial leaflets mounted on a titanium stent. During implantation, if the stent posts are indented, the structural deformation may be permanent 
and can cause altered hemodynamics with low gradients and reduced PPM. Therefore, the prosthesis must be implanted with extreme caution, to avoid any deviation of the titanium stent. Lower PPM values, and severe PPM, may be partially attributed to permanent titanium stent deviation during implantation.

\section{Limitations}

The present study is limited by several factors. First, most studies have reported only early hemodynamic and safety outcomes, limiting the data available for analysis. Results from early outcomes are promising, with the valve demonstrating excellent early EOA and acceptable mean gradients. However, longer-term follow-up definitely is warranted to balance the risks and benefits of this new, third-generation prosthesis.

Second, the available evidence included in this review is limited to observational studies, which are susceptible to selection bias and publication bias. Ideally, randomized controlled trials would provide the best evidence base for an assessment of the valve. Several included studies consisted of small sample sizes with populations of $<100$ patients, which prevented further meta-regression analysis to determine potential risk factors. Other limiting factors include the varied proportion of concomitant valvular and bypass procedures performed during AVR with the prosthesis, which may undermine the validity of the presented results. Future directions may include studies that compare the valve directly with stentless aortic prostheses, as well as current-generation bioprostheses, on long-term safety and hemodynamic outcomes.

\section{CONCLUSIONS}

Early safety and hemodynamic outcomes are excellent, providing acceptable mean gradients. Future long-term follow-up and randomized trials are warranted to confirm the early results with use of this prosthesis.

\section{Conflict of Interest Statement}

M.M. has received lecture funding from St Jude Medical. The other authors have nothing to disclose with regard to commercial support.

\section{References}

1. Bavaria JE, Desai ND, Cheung A, Petracek MR, Groh MA, Borger MA, et al. The St Jude Medical Trifecta aortic pericardial valve: results from a global, multicenter, prospective clinical study. J Thorac Cardiovasc Surg. 2014;147:590-7.

2. Wendt D, Thielmann M, Plicht B, Aßmann J, Price V, Neuhäuser M, et al. The new St Jude Trifecta versus Carpentier-Edwards Perimount Magna and Magna Ease aortic bioprosthesis: Is there a hemodynamic superiority? J Thorac Cardiovasc Surg. 2014;147:1553-60.

3. Ugur M, Suri RM, Daly RC, Dearani JA, Park SJ, Joyce LD, et al. Comparison of early hemodynamic performance of 3 aortic valve bioprostheses. J Thorac Cardiovasc Surg. 2014;148:1940-6.

4. Permanyer E, Estigarribia A-J, Ysasi A, Herrero E, Semper O, Llorens R. St. Jude Medical Trifecta aortic valve perioperative performance in 200 patients. Interact Cardiovasc Thorac Surg. 2013;17:669-72.
5. Dell'Aquila AM, Schlarb D, Schneider SRB, Sindermann JR, Hoffmeier A, Kaleschke G, et al. Clinical and echocardiographic outcomes after implantation of the Trifecta aortic bioprosthesis: an initial single-centre experience. Interact Cardiovasc Thorac Surg. 2013;16:112-5.

6. Moher D, Liberati A, Tetzlaff J, Altman DG. Preferred reporting items for systematic reviews and meta-analyses: the PRISMA statement. $\mathrm{Br}$ Med $\mathrm{J}$. 2009;339:b2535.

7. Stroup DF, Berlin JA, Morton SC, Olkin I, Williamson GD, Rennie D, et al. Meta-analysis of observational studies in epidemiology: a proposal for reporting Meta-analysis of Observational Studies in Epidemiology (MOOSE) group. JAMA. 2000;283:2008-12.

8. Yadlapati A, Diep J, Barnes M, Grogan T, Bethencourt DM, Vorobiof G. Comprehensive hemodynamic comparison and frequency of patient-prosthesis mismatch between the St. Jude Medical Trifecta and Epic Bioprosthetic aortic valves. J Am Soc Echocardiogr. 2014;27:581-9.

9. Ugur M, Byrne JG, Bavaria JE, Cheung A, Petracek M, Groh MA, et al. Suture technique does not affect hemodynamic performance of the small supraannular trifecta bioprosthesis. J Thorac Cardiovasc Surg. 2014;148:1347-51.

10. Seo H, Tsutsumi Y, Monta O, Numata S, Yamazaki S, Yoshida S, et al. Early outcomes and hemodynamics after implantation of the Trifecta aortic bioprosthesis. Gen Thorac Cardiovasc Surg. 2014;62:422-7.

11. Remadi JP, Levy F, Szymanski C, Nzomvuama A, Zogheib E, Gun M, et al. Early hemodynamics results of aortic valve replacement with the new St Jude Trifecta bioprosthesis. Int J Cardiol. 2014;174:755-7.

12. Modi A, Budra M, Miskolczi S, Velissaris T, Kaarne M, Barlow CW, et al Hemodynamic performance of Trifecta: single-center experience of 400 patients. Asian Cardiovasc Thorac Ann. 2015;23:140-5.

13. Levy F, Donal E, Biere L, Szymanski C, Remadi JP, Flécher E, et al Hemodynamic performance during exercise of the new St. Jude Trifecta aortic bioprosthesis: results from a French multicenter study. J Am Soc Echocardiogr. 2014;27:590-7.

14. Maruyama M, Daimon M, Kawata T, Kasai T, Ichikawa R, Miyazaki S, et al. Early hemodynamic performance of the Trifecta bioprosthetic valve in patients with aortic valve disease. Circ J. 2014;78:1372-8.

15. Minardi G, Pergolini A, Zampi G, Pulignano G, Pero G, Sbaraglia F, et al. St. Jude Trifecta versus Carpentier-Edwards Perimount Magna valves for the treatment of aortic stenosis: comparison of early Doppler-echocardiography and hemodynamic performance. Monaldi Arch Chest Dis. 2013;80:126-32.

16. Hanke T, Charitos EI, Paarmann H, Stierle U, Sievers HH. Haemodynamic performance of a new pericardial aortic bioprosthesis during exercise and recovery: comparison with pulmonary autograft, stentless aortic bioprosthesis and healthy control groups. Eur J Cardiothorac Surg. 2013;44:e295-301.

17. Saxena P, Greason KL, Schaff HV. Early structural valve deterioration of the Trifecta aortic valve biological prosthesis: a word of caution. J Thorac Cardiovasc Surg. 2014;147:e10-11.

18. Gerosa G, Tarzia V, Rizzoli G, Bottio T. Small aortic annulus: the hydrodynamic performances of 5 commercially available tissue valves. J Thorac Cardiovasc Surg. 2006;131:1058-64.

19. Totaro P, Degno N, Zaidi A, Youhana A, Argano V. Carpentier-Edwards perimount magna bioprosthesis: a stented valve with stentless performance? J Thorac Cardiovasc Surg. 2005;130:1668-74.

20. Rao V, Jamieson WR, Ivanov J, Armstrong S, David TE. Prosthesis-patient mismatch affects survival after aortic valve replacement. Circulation. 2000; 102(19 Suppl 3):III5-9.

21. Head SJ, Mokhles MM, Osnabrugge RL, Pibarot P, Mack MJ, Takkenberg JJ, et al. The impact of prosthesis-patient mismatch on long-term survival after aortic valve replacement: a systematic review and meta-analysis of 34 observational studies comprising 27,186 patients with 133,141 patient-years. Eur Heart J. 2012;33:1518-29.

22. Pibarot P, Dumesnil JG, Jobin J, Cartier P, Honos G, Durand LG. Hemodynamic and physical performance during maximal exercise in patients with an aortic bioprosthetic valve: comparison of stentless versus stented bioprostheses. J Am Coll Cardiol. 1999;34:1609-17.

23. Ali A, Halstead JC, Cafferty F, Sharples L, Rose F, Coulden R, et al. Are stentless valves superior to modern stented valves? A prospective randomized trial Circulation. 2006;114(1 Suppl):I535-40.

24. Borger MA, Prasongsukarn K, Armstrong S, Feindel CM, David TE. Stentles aortic valve reoperations: a surgical challenge. Ann Thorac Surg. 2007;84: 737-43; discussion 743-4.

Key Words: Aortic valve, replacement, outcomes 


\section{APPENDIX E1. MEDLINE (OVID) SEARCH}

\section{STRATEGY}

1. aortic adj3 (implant\$ or valv\$ or insert\$ or replac\$ or approach $\$$ or surgery or operation).mp.

2. Trifecta.mp.

3. Heart Valve Prosthesis/

4. or/1-3

5. Aortic Valve Stenosis/

6. aortic valve stenosis.mp.

7. valvular aortic stenosis.mp.

8. exp Heart Valve Diseases/

9. aortic valv\$ disease\$.mp.

10. heart valve disease\$.mp.

11. or $/ 5-10$

12. 4 and 11 
TABLE E1. Assessment of quality of included studies

\begin{tabular}{|c|c|c|c|c|c|c|c|}
\hline First author & $\begin{array}{c}\text { Clear definition } \\
\text { of study } \\
\text { population }\end{array}$ & $\begin{array}{c}\text { Clear definition } \\
\text { of outcomes and } \\
\text { outcome assessment }\end{array}$ & $\begin{array}{c}\text { Independent } \\
\text { assessment of } \\
\text { outcome } \\
\text { parameters }\end{array}$ & $\begin{array}{c}\text { Sufficient duration } \\
\text { of follow-up? }\end{array}$ & $\begin{array}{c}\text { Sufficient } \\
\text { sample size? }\end{array}$ & $\begin{array}{l}\text { No selective } \\
\text { loss during } \\
\text { follow-up? }\end{array}$ & $\begin{array}{c}\text { Important } \\
\text { confounders and } \\
\text { prognostic factors } \\
\text { identified? }\end{array}$ \\
\hline Yadlapati $^{8}$ & Yes & Yes & Yes & Yes & No & Yes & Yes \\
\hline Wendt $^{2}$ & Yes & Yes & Yes & No & Yes & Yes & Yes \\
\hline Ugur $^{9}$ & Yes & Yes & Yes & Yes & Yes & Yes & Yes \\
\hline $\mathrm{Seo}^{10}$ & Yes & Yes & Yes & No & No & Yes & Yes \\
\hline Remadi $^{11}$ & Yes & Yes & Yes & Yes & Yes & Yes & Yes \\
\hline Modi $^{12}$ & Yes & Yes & Yes & Yes & Yes & Yes & Yes \\
\hline Maruyama $^{14}$ & Yes & Yes & Yes & No & No & Yes & Yes \\
\hline Levy $^{13}$ & Yes & Yes & Yes & No & No & Yes & Yes \\
\hline Bavaria $^{1}$ & Yes & Yes & Yes & No & Yes & Yes & Yes \\
\hline Permanyer $^{4}$ & Yes & Yes & Yes & No & Yes & Yes & Yes \\
\hline Minardi $^{15}$ & Yes & Yes & Yes & No & No & Yes & Yes \\
\hline Hanke $^{16}$ & Yes & Yes & Yes & No & No & Yes & Yes \\
\hline Dell' Aquila $^{5}$ & Yes & Yes & Yes & No & No & Yes & Yes \\
\hline
\end{tabular}

TABLE E2. Baseline characteristics

\begin{tabular}{|c|c|c|c|c|c|c|c|c|c|c|c|c|c|c|c|c|c|c|c|}
\hline First author & Age (y) & Male & $\operatorname{BSA}\left(\mathbf{m}^{2}\right)$ & $\mathbf{A S}^{4}$ & $\mathbf{A R}$ & LVEF & CAD & HTN & $\begin{array}{c}\text { Hyper- } \\
\text { lipidemia }\end{array}$ & DM & COPD & $\begin{array}{l}\text { Pulm } \\
\text { HTN }\end{array}$ & CVA & $\mathbf{A F}$ & CKD & PVD & $\begin{array}{c}\text { Prior } \\
\text { surgery }\end{array}$ & $\begin{array}{c}\text { Euro- } \\
\text { SCORE }\end{array}$ & $\begin{array}{c}\text { NYHA } \\
\text { class } \\
\text { III/IV } \\
\end{array}$ \\
\hline Yadlapati $^{8}$ & $71.9(11.1)$ & 68 & $1.92(0.23)$ & NR & NR & $60 \pm 14$ & 36 & 92 & 80 & NR & 6.7 & NR & 18.7 & 42.7 & 4 & NR & NR & NR & NR \\
\hline Wendt ${ }^{2}$ & $72.2 \pm 6.7$ & 70.2 & $1.9 \pm 0.3$ & NR & NR & $50.5 \pm 13.4$ & 64.5 & 76 & NR & 28.9 & 18.2 & 14 & NR & 17.4 & 9.1 & 20.7 & 5.8 & $15.8 \pm 13.4^{*}$ & NR \\
\hline Ugur $^{9}$ & $75.5 \pm 8.1$ & 29.5 & NR & NR & NR & NR & 57.5 & 83.8 & NR & 24.9 & NR & NR & NR & NR & NR & NR & 22.3 & NR & 55.5 \\
\hline $\mathrm{Seo}^{10}$ & $75 \pm 9$ & 39.1 & $1.49 \pm 0.18$ & 87 & 8.7 & NR & 39.1 & 70 & 61 & 0 & NR & NR & 26 & 22 & 0 & NR & 4 & NR & 52.2 \\
\hline Remadi $^{11}$ & $75.2 \pm 7.5$ & 57 & NR & 91 & 17 & $60.4 \pm 10.8$ & 49 & 75 & NR & 8 & 16 & 5.4 & NR & 5 & 17 & 13 & 5 & $9.28 \pm 4.19$ & 37.0 \\
\hline Modi $^{12}$ & $75.9 \pm 8.5$ & 49 & $1.88 \pm 0.2$ & 91 & 6.5 & NR & 44 & 65 & 51 & 22 & NR & NR & NR & NR & NR & NR & 7.5 & NR & NR \\
\hline Maruyama $^{14}$ & $75.8 \pm 6.0$ & 27.3 & $1.50 \pm 0.16$ & 69.7 & 24.2 & $63.3 \pm 12.8$ & 24.2 & 78.8 & 48.5 & 27.3 & NR & NR & 15.2 & 15.2 & 6.1 & NR & NR & $3.5 \pm 5.1$ & 18.2 \\
\hline Levy $^{13}$ & $76 \pm 8$ & 58 & $1.84 \pm 0.18$ & NR & NR & $60 \pm 12$ & 34 & 76 & NR & 27 & NR & NR & NR & NR & NR & NR & NR & NR & NR \\
\hline Bavaria $^{1}$ & $72.5 \pm 9.0$ & 64.1 & NR & NR & NR & NR & 58.2 & 81.9 & 71.2 & 24.8 & NR & 17.3 & 13 & & 7 & 10.9 & 28 & NR & 49.3 \\
\hline Permanyer $^{4}$ & $71.18 \pm 7.7$ & 57.5 & $1.86 \pm 0.2$ & 64.5 & 13.5 & NR & NR & 72 & 37 & 40 & 10 & NR & NR & 17 & 11 & NR & 6.5 & 3.98 & 75.0 \\
\hline Minardi $^{15}$ & $75.5 \pm 5$ & 36 & $1.78 \pm 0.16$ & NR & NR & $58 \pm 11$ & NR & 12 & 24 & 18 & 22 & NR & 4 & 4 & NR & 26 & 6 & NR & 50.0 \\
\hline Hanke $^{16}$ & $71 \pm 7$ & 59.4 & $1.9 \pm 0.21$ & 50 & 21.9 & $59.00 \pm 13.08$ & 59.4 & 90.6 & NR & 28.1 & NR & NR & NR & NR & NR & NR & NR & NR & NR \\
\hline Dell' Aquila $^{5}$ & $74.65 \pm 7.63$ & 47.1 & $1.95 \pm 0.2$ & 91.4 & 1.6 & NR & NR & 91.4 & 64.3 & 22.9 & 14.3 & NR & NR & 12.9 & NR & 10 & NR & $8.36 \pm 2.64$ & NR \\
\hline Minimum & 71 & 27.3 & 1.49 & 50 & 1.6 & 50.5 & 24.2 & 12 & 24 & 0 & 6.7 & 5.4 & 4 & 4 & 0 & 10 & 4 & NA & 18.2 \\
\hline Maximum & 76 & 70.2 & 1.95 & 91.4 & 24.2 & 63.3 & 64.5 & 92 & 80 & 40 & 22 & 17.3 & 26 & 42.7 & 17 & 26 & 28 & NA & 75.0 \\
\hline Weighted & 73.7 & 54.7 & 1.9 & 82.4 & 10.3 & 57.7 & 53.1 & 77.1 & 61.5 & 24.8 & 13.6 & 16.0 & 13.3 & 6.7 & 8.0 & 12.4 & 18.6 & NA & 52.2 \\
\hline
\end{tabular}

\footnotetext{
Values are \%, unless otherwise indicated. Wendt, Remadi, and Modi used logistic EuroSCORE. Dell'Aquila used additive Euroscore. Permanyer did not report type of Euroscore used. $B S A$, Body surface area; $A S$, (predominant) aortic stenosis; $A R$, aortic regurgitation; $L V E F$, left ventricular ejection fraction; $C A D$, coronary artery disease; $H T N$, hypertension; $D M$, diabetes mellitus; $C O P D$, chronic obstructive pulmonary disease; Pulm, pulmonary; $C V A$, cerebral vascular accident; $C K D$, chronic kidney disease; $P V D$, peripheral vascular disease; EuroSCORE, European System for Cardiac Operative Risk Evaluation; NYHA, New York Heart Association; $N R$, not reported; $N A$, not available; $A F$, atrial fibrillation. *Non-logistic EuroSCORE.
} 